\title{
The effect of a wheelchair with pelvic support belt on respiratory function
}

\author{
Hiroshi Goda ${ }^{*}$, Mariko Nakai ${ }^{2}$, Hirotoshi Kishigami ${ }^{1}$ and Tatsuo Hatta ${ }^{1}$ \\ ${ }^{1}$ Department of Occupational Therapy, Faculty of Health Sciences, Japan Health Care College, Japan \\ ${ }^{2}$ Department of Rehabilitation, Chiba Rehabilitation Center, Japan
}

\begin{abstract}
Decreased respiratory function is associated with a slouched posture in a wheelchair for elderly persons with severe kyphosis. We compared the use of a wheelchair with a pelvic support belt and standard wheelchair use in persons with severe kyphosis. The subjects were 22 healthy individuals. We assessed head, neck, and trunk posture; forced vital capacity (FVC), percent predicted forced expiratory volume in 1 second $\left(\mathrm{FEV}_{1}\right)$, tidal volume $(\mathrm{VT})$, respiratory frequency, $\mathrm{VO}_{2}$, and $\mathrm{VCO}_{2}$ We found that the use of a wheelchair equipped with a pelvic support belt improved head and neck alignment and reduced forward motion in the trunk. No significant differences between the two types of wheelchairs were found in terms of $\mathrm{VO}_{2}$ and $\mathrm{VCO}_{2}$. However, use of a wheelchair with a pelvic support belt was associated with increases in FVC and $\mathrm{FEV}_{1}$. Additionally, use of a wheelchair with a pelvic support belt was associated with greater VT and was larger than that of WC. And the respiratory frequency in those using a wheelchair with a pelvic support belt was smaller than that of WC. The postural changes that resulted from the use of a wheelchair with a pelvic support belt were found to improve respiratory functioning by increasing the tidal volume through enlargement of the thorax and decreases in respiratory frequency.
\end{abstract}

\section{Introduction}

The wheelchair is an important ambulatory aid for elderly disabled individuals [1]. The standard type wheelchair is widely utilized among most of these individuals. The back support of the standard type wheelchair comprises two parallel rods and a flat cover, which does not support individuals with kyphosis. As the trunk is pushed forward, these individuals exhibited a Forward Head Posture [2-4]. FHP not only fatigues the erector spinae muscle but also increases the integrated muscle activity of the suprahyoid muscle during swallowing [5,6]. Also, especially, for elderly persons with severe kyphosis, the pelvis tends to slide forward [7], resulting in a posterior tilt of the pelvis [3]. A posterior tilt of the pelvis promotes the plating of the lumbar spinae and worsens the kyphosis [8]. Because of the pushing of the abdominal cavity and thoracic cavity that occurs with slouching, respiratory function is reduced [9].

Rehabilitation staff assist disabled elderly persons to address these postural malalignments. As most therapists know the importance of pelvic stability, they attach a cushion or pad to the trunk of the wheelchair user [8]. However, many wheelchair users experienced discomfort while sitting [7]. Nishimura developed the active balance seated wheelchair (ABSW). The ABS wheelchair was developed based on ABS theory. The ABSW maintains appropriate head and neck alignment $[10,11]$. To attain this posture, the pelvic and thoracic support belts support the trunk. The pelvic support belt supports the pelvis like an arch, while the thoracic support belt supports the lower thorax. Many reports have suggested that respiratory function is affected by changes in posture, such as standing or sitting [11-13]. However, there are few studies on wheelchairs and chairs $[14,15]$. Thus, this study aimed to clarify that use of an ABSW improves respiratory functioning. Because this is a first step, the subjects were healthy individuals.

\section{Materials and methods}

Twenty-two healthy individuals were selected (Table 1). Individuals with a history of respiratory disease were excluded. Ethical approval was obtained from the Ethics Review Committee, Faculty of Health Sciences, Hokkaido University (14-78) and written informed consent was obtained prior to testing.

\section{Methods}

We used two wheelchairs: Zaou (development code NA-501) for the ABSW (Figure 1) and a standard wheelchair (development code NA400) as the control (Nissin Medical Industries, Japan for both). Zaou has a function allowing it to respond by adjusting the tension of the pelvic support belt to the posture in which elderly disabled individuals sit, with the posterior pelvis inclined. However, the setting with the pelvic support belt is the standard setting.

In the standard wheelchair, individuals sit in the posture that is often seen as an elderly person's posture. The hand support handle of the back support was folded, and the great trochanter was moved $5 \mathrm{~cm}$ forward from the state of sitting down deeply. After that, the back support was raised from behind. We set a target for individuals to see, and the height of target is 1.2 meters from the floor. Besides, we instructed the

Correspondence to: Hiroshi Goda, Department of Occupational Therapy, Faculty of Health Sciences, Japan Health Care College, Megumino Nishi -6 chome, 061-1373 Eniwa, Japan, Tel: +081 123-29-3171, Fax: +081 123-37-4525, E-mail: h_goda@nihoniryo-c.ac.jp

Key words: respiratory function, seated posture, wheelchair

Received: January 2, 2018; Accepted: February 07, 2018; Published: February 13,2018 
A

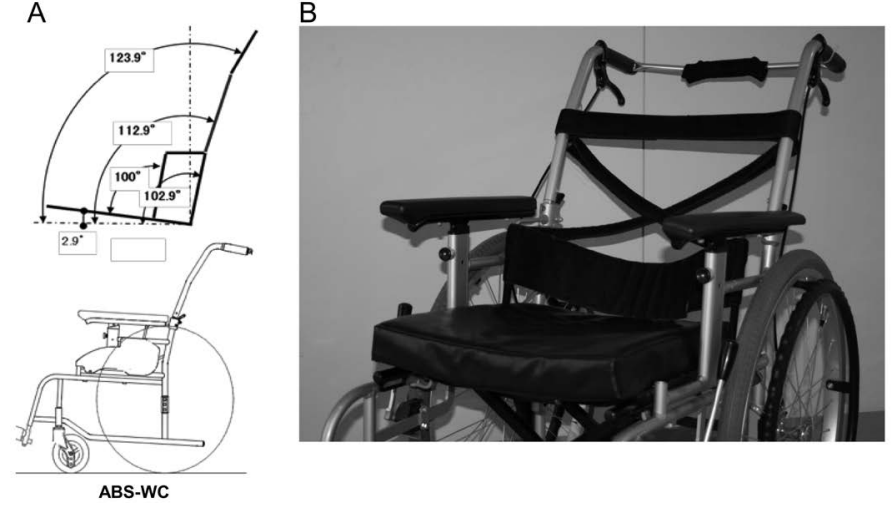

Figure 1. The wheelchair that we used in this experiment (active balance seated wheelchair); (a) shows the angle of back support, and (b) shows the stretched support belt. The pelvic support belt is stretched like an arch, as viewed from above. The thoracic support belts are stretched to cross over each other.

Table 1. Demographic data of individuals $(n=22)$.

\begin{tabular}{|c|c|c|}
\hline & Male $(\mathrm{n}=11)$ & Female $(\mathrm{n}=12)$ \\
\hline Age (years) & $22.36 \pm 0.64$ & $23.0 \pm 1.6$ \\
\hline Height $(\mathrm{cm})$ & $172.11 \pm 3.89$ & $155.81 \pm 6.36$ \\
\hline Weight $(\mathrm{kg})$ & $62.09 \pm 6.55$ & $49.98 \pm 5.37$ \\
\hline
\end{tabular}

individuals to look forward the target. The individuals were instructed not to release the trunk from the back support (Figure 2).

\section{Measurement and analysis of posture and gas exchange}

Sitting in each chair took 5 minutes. This time was needed to acclimate to the chair, find a comfortable position, and regulate breathing [14]. After that, we assessed the subject's posture and measured the gas exchange.

To assess the posture, surface landmarks of the neck and trunk were identified and marked by placing an adhesive reflective ball on the C7 spinous process, tragus of an ear, great trochanter, patella, and lateral malleolus of the individuals. Reflective balls were stuck to the skin using double-sided tape. For each individual, sagittal photographs of the neck and trunk were taken from the right-hand side using a 2.07 megapixel digital camera (Canon iVIS HF M43, Japan). The position of each marker was recorded and automatically digitized using Dartfish software (Dartfish Co., Ltd., Lausanne, Switzerland).

Postural analysis is performed on two points: position and attitude. For position, the head angle, neck angle, and trunk angle are measured. The definition of each angle is shown below [13,16-19].

- Head angle is the angle between the line from the lateral orbital rim to the tragus and the horizontal angle.

- Cervical angle is the angle between the line from the tragus to the $\mathrm{C7}$ spinous process and the horizontal angle.

- Trunk angle is the angle between the C7 spinous and the greater trochanter and the horizontal angle.

Attitude is as follows [13,16-19].

- Head joint angle is the angle between the line of the lateral orbital rim and tragus and the line connecting the tragus and $\mathrm{C} 7$ spinous process.

- Cervical joint angle is the angle between the line tragus and C7 spinous process and the line connecting the $\mathrm{C} 7$ spinous process and the greater trochanter.
- Trunk joint angle is the angle between the line C7 spinous process and the greater trochanter and the line connecting the greater trochanter and patella.

Gas exchange was measured for tidal volume (VT), respiration rate/ minute (Rf), and $\mathrm{VO}_{2}$ and $\mathrm{VCO}_{2}$. We used Quark CPET (COSMED) as the measuring instrument and calibrated it before the experiment. In the measurement, after giving a mask to the participants, we instructed them to see the target in front and urged them to rest for approximately 5 minutes (Figure 2). The resting breath for the following 5 minutes was recorded. Then, we analyzed the last 3 minutes and calculate the average value.

\section{Pulmonary function testing}

Following the gas exchange measurement, a pulmonary function test using a spirometer was performed. Respiratory function was measured for forced vital capacity (FVC) and forced expiratory volume in 1 second $\left(\mathrm{FEV}_{1}\right)$. The spirometry was completed using a Master Scope PC spirometer (Minato, AS-507, Osaka, Japan) that was calibrated prior to testing. The tests were repeated 3 times according to the standard maneuver criteria previously described [20]. We practiced in order to minimize the effect of the trunk.

\section{Statistical analysis}

The posture, gas exchange, and spirometer values were determined and compared between the Zaou and standard wheelchair using a paired $t$-test with the level of significance set at $P<0.05$. Statistical analyses were performed using Statistical Package for the Social Sciences software (version 25; IBM).

\section{Results}

\section{Statistical power}

The statistical power was found to be 0.87 (effect size $=0.5, \beta / \alpha$ ratio $=1$, and total sample size $=22$ ).

\section{Comparison of posture between wheelchair types}

The mean \pm SD head angle was $31.01 \pm 6.88^{\circ}$ for the Zaou and 26.97 $\pm 7.7^{\circ}$ for the standard wheelchair. The mean \pm SD neck angle was 54.37 $\pm 5.08^{\circ}$ for the Zaou and $40.44 \pm 8.25^{\circ}$ for the standard wheelchair. The mean \pm SD trunk angle was $125.67 \pm 3.95^{\circ}$ for the Zaou and $114.05 \pm$ $3.18^{\circ}$ for the standard wheelchair. There was a significant difference in all angles between the wheelchairs types (Table 2).

The mean \pm SD cervical joint angle was $108.08 \pm 5.23^{\circ}$ for the Zaou and $106.48 \pm 7.38^{\circ}$ for the standard wheelchair. No significant
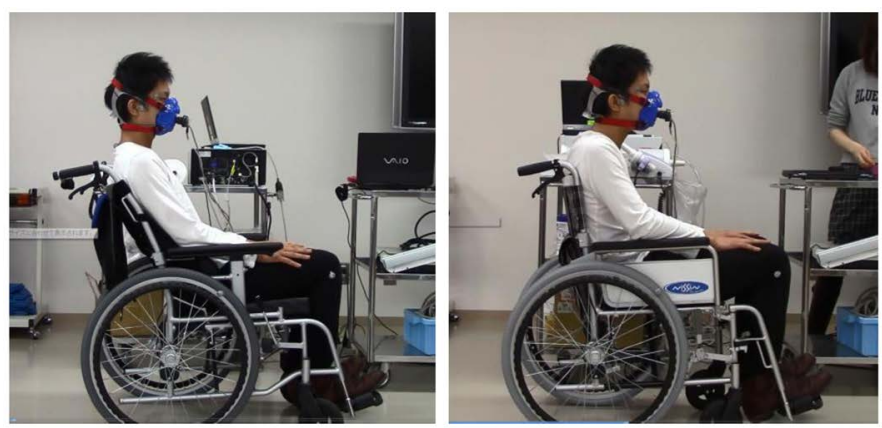

Figure 2. Postures of the experiment. Individuals sit in the ABSW (left), and in a standard wheelchair (right). The pelvis support belt was set at the standard setting, and the individual sits the pelvis down to the preset depth. In the standard wheelchair, individuals sit with their pelvis sliding forward. After that, the back support is set to the original position. 
differences between the two types of wheelchairs were found. The mean \pm SD head joint angle was $156.65 \pm 7.28^{\circ}$ for the Zaou and $165.88 \pm 9.86^{\circ}$ for the standard wheelchair; the mean \pm SD trunk angle was $116.18 \pm$ $5.9^{\circ}$ for the Zaou and $116.88 \pm 6.26^{\circ}$ for the standard wheelchair. The differences in neck joint angle and trunk joint angle between users of the two types of wheelchairs were found to be significant (Table 3).

\section{Comparison of gas exchange and spirometer values between wheelchair types}

The mean \pm SD FVC was $2.67 \pm 0.77 \mathrm{~L}$ for the Zaou and $2.25 \pm 0.67 \mathrm{~L}$ for the standard wheelchair. The mean $\pm \mathrm{SD} \mathrm{FEV}_{1}$ was $2.33 \pm 0.84 \mathrm{~L}$ for the Zaou and $1.93 \pm 0.68 \mathrm{~L}$ for the standard wheelchair. The differences in both of these values in the two types of wheelchairs were found to be significant (Table 4).

The mean \pm SD VT was $0.5 \pm 0.21 \mathrm{~L}$ for the Zaou and $0.46 \pm 0.15 \mathrm{~L}$ for the standard wheelchair. The mean \pm SD Rf was $15.93 \pm 3.87$ for the Zaou and $17.24 \pm 3.69$ for the standard wheelchair. VT and Rf values were significantly higher in the Zaou than in standard wheelchair users. There were no significant differences between groups in $\mathrm{VO}_{2}$ and $\mathrm{VCO}_{2}$ (Table 5).

\section{Discussion}

The purpose of this study was to clarify that use of the Zaou improves respiratory function. Calories consumed at rest are approximately 1.01.2 calories (kcal) per minute. At this time, the amount of oxygen to be taken in and consumed in the body is set to approximately $0.2-0.25 \mathrm{~L}$ per minute, and when this oxygen intake is divided by the weight of the person, on average, it is $3.5 \mathrm{ml}$ per kg body weight per minute [21]. A large oxygen uptake indicates that calorie consumption is high in the seated position.

In this study, there were no significant differences in oxygen intake or in carbon dioxide production. Therefore, it can be concluded that there were no differences in energy expenditure due to postural differences. However, the ways of ingesting oxygen differed between the two groups. In other words, in the standard wheelchair users, the tidal

Table 2. The difference in position between wheelchairs.

\begin{tabular}{|c|c|c|c|}
\hline & SW & Zaou & P value \\
\hline Head angle & $27.0 \pm 7.7^{\circ}$ & $31.0 \pm 6.7^{\circ}$ & 0.02 \\
\hline Cervical angle & $40.4 \pm 8.3$ & $54.4 \pm 5.1$ & $<0.01$ \\
\hline Trunk angle & $114.15 \pm 3.2$ & $125.7 \pm 4.0$ & $<0.01$ \\
\hline
\end{tabular}

Table 3. The differences in attitude between wheelchairs.

\begin{tabular}{|c|c|c|c|}
\hline & SW & Zaou & P value \\
\hline Heal joint angle & $165.9 \pm 9.9^{\circ}$ & $156.7 \pm 7.328^{\circ}$ & $<0.01$ \\
\hline Cervical joint angle & $106.5 \pm 7.4^{\circ}$ & $108.1 \pm 5.2^{\circ}$ & 0.23 \\
\hline Trunk joint angle & $102.9 \pm 6.3$ & $116.2 \pm 6.0^{\circ}$ & $<0.01$ \\
\hline
\end{tabular}

Table 4. Comparisons of $\mathrm{FVC}$ and $\mathrm{FEV}_{1}$ between wheelchairs.

\begin{tabular}{|c|c|c|c|}
\hline & SW & Zaou & P value \\
\hline FVC(L) & $2.25 \pm 0.67$ & $2.67 \pm 0.77$ & $<0.01$ \\
\hline FEV $_{1}(\mathrm{~L})$ & $1.93 \pm 0.68$ & $2.33 \pm 0.84$ & $<0.01$ \\
\hline
\end{tabular}

Table 5. Comparisons of gas exchange values between wheelchairs.

\begin{tabular}{|c|c|c|c|}
\hline & SW & Zaou & P value \\
\hline $\mathrm{VT}(\mathrm{L})$ & $0.46 \pm 0.15^{\circ}$ & $0.5 \pm 0.21^{\circ}$ & 0.04 \\
\hline $\mathrm{Rf}($ breaths/min) & $17.24 \pm 3.69$ & $15.93 \pm 3.87$ & 0.02 \\
\hline $\mathrm{VO}_{2}(\mathrm{ml} / \mathrm{min})$ & $202.93 \pm 66.25$ & $203.41 \pm 67.86$ & n.s. \\
\hline $\mathrm{VCO}_{2}(\mathrm{ml} / \mathrm{min})$ & $163.34 \pm 56.48$ & $165.16 \pm 56.11$ & n.s. \\
\hline
\end{tabular}

volume was small and the breathing frequency was high, whereas in the ABSW, users the tidal volume was large and the breathing frequency was low.

In the pulmonary function test measured by the spirometer, the FVC of the standard wheelchair users was significantly lower. Individuals in this study were healthy, and despite the fact that there were no problems in respiratory function, the reduction in vital capacity of effort was thought to be because the wheelchair posture restricted the movement of the ribcage.

\section{Influence of standard wheelchair on breathing function}

The back support rod of the standard wheelchair is attached at $96^{\circ}$ to the seat. Between two rods, it is stretched with a flat seat. The thorax and pelvis of an elderly person using a wheelchair are curved when viewed from above, and in contact with a flat back support in a small area [3]. It is also clear that straight back support pushes the subject's trunk forward $[3,10]$. This research was an experiment for healthy subjects, but in order to mimic elderly disabled people, we slid their pelvis forward and sat down. Sliding the pelvis forward prompts the pelvis to tilt backward. The posterior tilt of the pelvis increases the kyphosis as well as flattens the lumbar vertebrae [22]. As a result, the exaggerated kyphosis was attached to a small area on the linear back support, and the trunk was pushed forward. Thus, it became slouched posture. Sasaki and colleagues showed the influence of differences in back support angles on breathing [23], in which healthy subjects sat in a reclining wheelchair and had their respiratory functioning assessed. The angle of the reclining wheelchair was set to the angle (BASE), BASE $+10^{\circ}$, BASE $-10^{\circ}$ which the subject feels is comfortable. They found the base angle to be $119^{\circ}$. Significant differences were observed between the BASE $+10^{\circ}$ and the BASE, and the BASE $+10^{\circ}$ and the BASE $10^{\circ}$, and the integrated muscle activity of the average muscle of the upper trapezium superficial fibers in the maximal inspiratory phase. In other words, it showed that the BASE $+10^{\circ}$ increases the muscle activity of the upper trapezius muscle fibers more than the BASE and BASE $-10^{\circ}$. This indicates that more muscle strength is needed to spread the collapsed thorax, which was pushed forward. In addition, people who have pain in the neck tend to raise the muscle activity of the upper trapezius muscle, and have a possibly altered movement pattern of the thorax during respiration [9]. Specifically, it was clarified that the increase of kyphosis decreases the FVC, the total ventilation volume, and the amount in 1 second [24,25]. We consider that the decrease in FVC and tidal volume are the result of the posture created by that standard wheelchair.

\section{Effect of wheelchair with pelvis support on respiratory function}

The Zaou used in this study has a completely different back support structure than the standard wheelchair. The rods of the back support are inclined backward. Between the two rods, the pelvic support belt forms an arc when viewed from above, and the thoracic support belt is stretched over the cloth. The pelvic support belt supports the pelvis curvilinear and prevents the pelvis from tilting backward. Preventing the posterior tilt of the pelvis mitigates the reinforcement of exaggerated kyphosis [22,26]. Furthermore, since the back support rods are tilted backward more than in the standard type wheelchair, it promotes the backward inclination of the trunk. Szczygiel and colleagues showed that the angle of back support is more than $95-100^{\circ}$, and $105-110^{\circ}$ is where the number of breaths becomes smaller [15]. A declining respiratory rate with the use of Zaou is supported by previous studies. 
The reason why Zaou contributed to the decrease in respiration rate is that the movement of the thorax caused by relaxation of the kyphosis has expanded. Elderly people with exaggerated kyphosis have limited movement in the ribs and reduced lateral expansion of the thorax. As a result, the total ventilation is reduced [27]. It is thought that Zaou promotes the backward inclination of the trunk, which contributes to alleviating the back curvature of the thoracic vertebrae and expands the mobility of the thorax cage.

\section{Conclusion}

ABSW promoted appropriate posture in head and neck alignment and improved respiratory functioning.

\section{Acknowledgments}

The authors would like to thank Enago (www.enago.jp) for the English language review.

\section{Funding}

The authors have no support or funding to report.

\section{Competing interests}

The authors declare that they have no competing interests.

\section{References}

1. Miura K, Kawagoe M, Koh S (2007) Difference between long-term care facilities in the same area focusing on walking support conditions: analysis of results of a questionnaire survey. Seikatukagakukenkyuushi 6: 1-8.

2. Nishimura S (2013) Science of the wheelchair and humans. Description of pelvic support model in active balance seating. Am J Occup Ther 30(1): 8-20. [Crossref]

3. Ukita A, Nishimura S, Kishigami H, Hatta T (2015) backrest shape affects head-neck alignment and seated pressure. J Healthc Eng 6(2): 179-192. [Crossref]

4. Hanten WP, Lucio RM, Russell JL, Brunt D (1991) Assessment of total head excursion and resting head posture. Arch Phys Med Rehabil 72(11): 877-880. [Crossref]

5. Goda H, Hatta T, Kishigami H, Yamada S, Ikeda T (2016) The effect of noveldeveloped product of wheelchair incorporating pelvic support to swallowing with forward head posture. Japanese Occupational Therapy Congress \& Expo 91(1): 42-42.

6. Sakuma T, Kida I (2010) Relationship between ease of swallowing and deglutitionrelated muscle activity in various postures. J Oral Rehabil 37(8): 583-589. [Crossref]

7. Shaw G, Taylor SJ (1991) A survey of wheelchair seating problems of the institutionalized elderly. Assistive Technology: The Official Journal of RESNA 3(1): 5-10. [Crossref]

8. Geyer MJ, Brienza DM, Karg P, Trefler E, Kelsey S (2001) A randomized control trial to evaluate pressure-reducing seat cushions for elderly wheelchair users. Adv Skin Wound Care 14(3): 120-129. [Crossref]

9. Kapreli E, Vourazanis E, Strimpakos N (2008) Neck pain causes respiratory dysfunction. Medical Hypotheses 70(5): 1009-1013. [Crossref]
10. Goda H, Hatta T, Kishigami H, Suzuki A, Ikeda T (2015) Does a novel-developed product of wheelchair incorporating pelvic support prevent forward head posture during prolonged sitting? PloS one 10(11): e0142617. [Crossref]

11. Sawada N, Hatta T, Kishigami H, Shimizu M, Yoda T, et al. (2015) The effect of a newly developed wheelchair with thoracic and pelvic support on cervical movement and muscle activity in healthy elderly women. European Geriatric Medicine 6: 286-290.

12. Ukita A, Abe M, Nikaido M, Arisawa K, Hatta T, et al. (2017) Does the backrest shape of the wheelchair in uence the asymmetric posture of patients with hemiparesis? A single institution pilot study. Biomed Res Clin Prac 2(4): 1-7. doi: 10.15761/ BRCP.1000149.

13. Goda H, Hatta T, Kishigami H, Ikeda T, Yamada S, et al. (2017) The effect of a wheelchair designed to prevent forward head posture on swallowing duration and integrated electromyography of suprahyoid muscles. Integr Mol Med 4 (3): 1-5.

14. Szczygiel E, Zielonka K, Mazur T, Metel S, Golec J (2015) Respiratory chest movement measurement as a chair quality indicator--preliminary observations. Int $J$ Occup Saf Ergon 21(2): 207-212. [Crossref]

15. Lin F, Parthasarathy S, Taylor SJ, Pucci D, Hendrix RW, et al. (2006) Effect of different sitting postures on lung capacity, expiratory flow, and lumbar lordosis. Arch Phys Med Rehabil 87(4): 504-509. [Crossref]

16. Kang JH, Park RY, Lee SJ, Kim JY, Yoon SR, et al. (2012) The effect of the forward head posture on postural balance in long time computer based worker. Ann Rehabil Med 36(1): 98-104. [Crossref]

17. Harrison AL, Barry-Greb T, Wojtowicz G (1996) Clinical measurement of head and shoulder posture variables. J Orthop Sports Phys Ther 23(6): 353-361. [Crossref]

18. Shahidi B, Haight A, Maluf K (2013) Differential effects of mental concentration and acute psychosocial stress on cervical muscle activity and posture. Journal of Electromyography and Kinesiology 23(5): 1082-1089. [Crossref]

19. Yip CH, Chiu TT, Poon AT (2008) The relationship between head posture and severity and disability of patients with neck pain. Manual Therapy 13(2): 148-154. [Crossref]

20. Miller MR, Hankinson J, Brusasco V, Burgos F, Casaburi R, et al. (2005) Standardization of spirometry. Eur Respir J 26(2): 319-338. [Crossref]

21. Ministry of health law. physical activity.movement [cited 2017 12/1]. Available from http://www1.mhlw.go.jp/topics/kenko21_11/b2.html.

22. Kuo YL, Tully EA, Galea MP (2009) Video analysis of sagittal spinal posture in healthy young and older adults. J Manipulative Physiol Ther 32(3): 210-215. [Crossref]

23. Sasaki K, Kamiya A, Maruo T, Kimura T (2012) The effect of reclining angles of wheelchair on spirometric indices and respiratory muscle activities. Rigakuryoho Kagaku 27(1): 7-10.

24. Lee SJ, Chang JY, Ryu YJ, Lee JH, Chang JH, et al. (2015) Clinical features and outcomes of respiratory complications in patients with thoracic hyperkyphosis. Lung 193(6): 1009-1015. [Crossref]

25. Han J, Park S, Kim Y, Choi Y, Lyu H (2016) Effects of forward head posture on forced vital capacity and respiratory muscles activity. J Phys Ther Sci 28(1): 128-131. [Crossref]

26. Quek J, Pua YH, Clark RA, Bryant AL (2013) Effects of thoracic kyphosis and forward head posture on cervical range of motion in older adults. Manual Therapy 18(1): 6571. [Crossref]

27. Culham EG, Jimenez HA, King CE (1994) Thoracic kyphosis, rib mobility, and lung volumes in normal women and women with osteoporosis. Spine 19(11): 1250-1255. [Crossref]

Copyright: (C2018 Goda H. This is an open-access article distributed under the terms of the Creative Commons Attribution License, which permits unrestricted use, distribution, and reproduction in any medium, provided the original author and source are credited. 